\title{
Optical Fiber Fabry-Perot Humidity Sensor Filled with Polyvinyl Alcohol
}

\author{
Ning Wang, Haosheng Zhang, Xiaodan Yu, Xiaolei Yin, \\ Yuhao Li, Yonggang Du, and Dailin Li \\ College of Science, China University of Petroleum (Huadong), \\ No. 66 Changjiang West Road, Qingdao, Shandong 266580, China
}

(Received December 19, 2020; accepted February 8, 2021)

Keywords: optical fiber sensor, Fabry-Perot, humidity measurement, temperature measurement, polyvinyl alcohol (PVA)

An optical fiber Fabry-Perot (F-P) humidity sensor was fabricated using polyvinyl alcohol (PVA) and a single-mode optical fiber. Humidity response experiments were carried out in the humidity range of $22-98 \% \mathrm{RH}$ with a cycle of rising and falling humidity to investigate the repeatability of its response to humidity. The sensitivity was $36.71 \mathrm{pm} / \%$ relative humidity (RH) with linearity of 0.99773 under rising humidity and $37.63 \mathrm{pm} / \% \mathrm{RH}$ with linearity of 0.99846 under falling humidity. The experimental results showed that the humidity sensor has good repeatability and consistency. Typical tests under $75 \% \mathrm{RH}$ were performed to obtain the dynamic response characteristics. The dynamic response wavelength drift was measured repeatedly, which showed a high response speed. The response time and recovery time were 1.5 and $2.5 \mathrm{~s}$, respectively. Furthermore, the dependence of the response characteristics on the cavity length and PVA concentration was investigated. The experimental results showed that the sensor maintains a highly linear response to humidity over a wide range of RH regardless of the cavity length and PVA concentration. The research results indicate the possibility of realizing an easily fabricated, low-cost, and high-performance optical fiber humidity sensor.

\section{Introduction}

With the development of industry and agriculture, humidity measurement has become more important. The application of optical fiber humidity sensors has particularly attracted attention in industry. ${ }^{(1-3)}$ The high sensitivity, fast response, simple structure, and low cost are the main considerations when applying optical fiber humidity sensors. As a traditional optical fiber sensor, the optical fiber Fabry-Perot (F-P) sensor has a simple structure, small size, strong multiplexing ability, high repeatability, ${ }^{(4,5)}$ and many applications, ${ }^{(6-8)}$ because of the combination of an optical fiber and an F-P interferometer. In recent years, optical fiber humidity sensors with this structure have also attracted widespread attention, ${ }^{(9-11)}$ which usually combine humidity-sensitive materials with fibers having special structures.

As a typical humidity-sensitive material, polyvinyl alcohol ${ }^{(12-14)}$ (PVA) is used in optical fiber humidity sensors. Huang et al. ${ }^{(15)}$ applied a humidity-sensitive chorion chloride and PVA

*Corresponding author: e-mail: qfwangning@163.com https://doi.org/10.18494/SAM.2021.3229 
film in a humidity sensor. Miao et al. ${ }^{(16)}$ proposed an air relative humidity (RH) sensor based on a tilted fiber grating (TFBG) cladding covered with PVA and successfully monitored RH in the range of $20-98 \%$. Zhu et al. ${ }^{(17)}$ studied a preparation method for aqueous solutions of PVA, conducted refractive index sensing experiments, and proposed a tapered optical fiber humidity sensor based on a PVA-aluminum film. Tang et al. ${ }^{(18)}$ fabricated a novel Mach-Zehnder (MZ) interference optical fiber humidity sensor by splicing a $15 \mathrm{~mm}$ single-mode optical fiber between two standard single-mode fibers. The single-mode part in the middle was coated with a layer of 5\% PVA, and the sensitivity of the humidity sensor was measured to be $0.0983 \mathrm{~nm} / \%$

RH. Bi et al. ${ }^{(19)}$ used a tapered single-mode fiber coated with PVA and an Al film as a humidity sensor. However, these optical fiber humidity sensors with PVA have a complex manufacturing process or a high cost, and it is very important to design an easily fabricated and low-cost optical fiber humidity sensor with good performance. Furthermore, in the reported research, the PVA was usually used only as a humidity response transducer because of the ring coating structure.

In this study, by filling an optical fiber F-P cavity with PVA, we developed a novel optical fiber F-P humidity sensor. Compared with some reported optical fiber F-P humidity sensors, this sensor uses low-cost materials (PVA and normal optical fibers) and has high sensitivity and a high response speed despite its simple fabrication. The sensor is directly fabricated using PVA and two normal single-mode optical fibers. Many optical fiber humidity sensors fabricated with various materials coating the periphery of the fibers have been reported. The coating ring structure is a kind of humidity-sensitive transducer. However, in our sensor, the PVA acts not only as a transducer of the humidity response but also as a direct transmission medium, which enables a more direct response to the humidity. Furthermore, PVA is transparent and adhesive, which is helpful for fabricating an optical fiber F-P cavity. The interference spectrum of the F-P cavity is affected by changes in the refractive index and cavity length caused by environmental humidity. We verified that this structure has a wide linear response and high sensitivity to environmental humidity, thus demonstrating the feasibility of developing an easily fabricated, low-cost, and high-performance optical fiber humidity sensor.

\section{Fabrication and Principle of the Sensor}

\subsection{Sensor fabrication}

PVA can quickly absorb and release moisture and has stable physical properties. This humidity-sensitive material is usually in the form of a powder with small particles that need to be formulated into a gel for coating. PVA is a high-molecular-weight polymer material with a large number of hydroxyl groups $(-\mathrm{OH})$, which enable it to easily absorb moisture, causing its volume to increase. If PVA is coated on an optical fiber sensor as a humidity-responding transducer, the interference spectrum of the F-P cavity will change with the humidity.

First, we prepared some PVA gel with $70 \mathrm{mg} / \mathrm{ml}$ concentration. We placed $7 \mathrm{~g}$ of PVA powder and $100 \mathrm{ml}$ of deionized water in a beaker. The mixture of PVA powder and deionized water was placed on a magnetic stirrer and heated until the PVA powder dissolved. Finally, the 
beaker was allowed to stand for $30 \mathrm{~min}$. The PVA completely dissolved in the water to form a transparent PVA gel.

The structure of the F-P optical fiber cavity sensor is shown in Fig. 1. Two single-mode fibers with flat end faces and PVA between them form the F-P cavity. Figure 1(a) is a schematic diagram of the structure and Fig. 1(b) is a photograph of the sensor taken during the fabrication. The optical fiber is a Corning SMF-28e single-mode fiber with $9 \mu \mathrm{m}$ core diameter, $125 \mu \mathrm{m}$ cladding diameter, and $10.4 \mu \mathrm{m}$ MFD (Mode Field Diameter) at $1550 \mathrm{~nm}$. First, we peeled off the coating layer of the single-mode fiber then cut the bare fiber with a fiber cleaver to obtain a relatively flat reflection end face, then fixed it on the fiber adjustment frame. We adjusted the position of the fiber adjustment frame to align the two fibers and obtain a good F-P cavity interference spectrum, as monitored by an MOI SM125 optical fiber sensor analyzer. After the spectrum stabilized, we used a burette to add 3-5 $\mathrm{ml}$ of PVA gel dropwise vertically into the optical fiber F-P cavity. To hold the PVA gel and prevent its diffusion, causing insufficient bonding, we placed a plastic gasket near the sensor, as shown in Fig. 1(b). After coating the PVA gel, we dried it for 3 to $5 \mathrm{~h}$ to obtain an optical fiber humidity sensor with a good interference spectrum. Then the sensor was experimentally investigated in environments with different humidity levels.

\subsection{Principle of sensor}

When the PVA gel film is affected by humidity, it expands and its refractive index changes, both of which cause the optical path difference of the two beams in Fig. 1(a) and the peak wavelength of the interference spectrum to change. The change in the optical path difference of the F-P cavity caused by external environment humidity is

$$
\Delta L=2\left(\Delta n_{e} d+n_{e} \Delta d\right)=L\left(\frac{\Delta n_{e}}{n_{e}}+\frac{\Delta d}{d}\right)
$$

where $n_{e}$ is the effective refractive index of PVA, $L$ is the optical path difference of the F-P cavity, and $d$ is the cavity length.

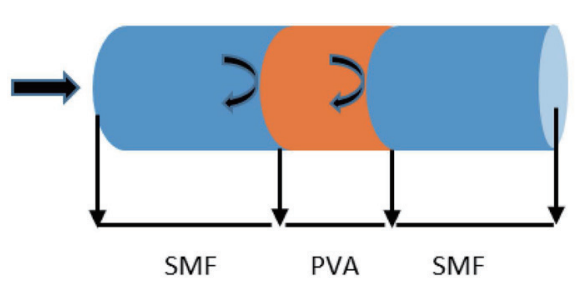

(a)

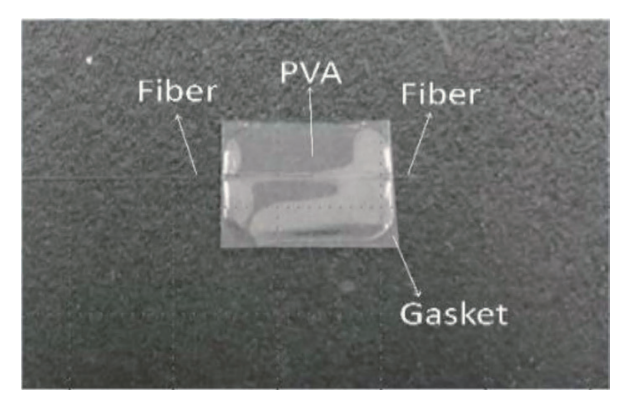

(b)

Fig. 1. (Color online) Structure of optical fiber F-P cavity sensor. (a) Sensor structure. (b) Photograph of sensor taken during fabrication. 
When water molecules enter the film, its volume increases in accordance with the law of volume addition: ${ }^{(20)}$

$$
\Delta V=\frac{V_{f}}{1-\Phi_{w}}
$$

Here, $V_{f}$ is the initial volume of the film and $\Phi_{w}$ is the volume fraction of water molecules absorbed by the film. In the F-P cavity sensor, the change in the film thickness (cavity length) $\Delta d$ is related to the PVA expansion effect:

$$
\begin{gathered}
\frac{\Delta d}{d}=\frac{1}{\gamma} \frac{\Phi_{w}}{1-\Phi_{w}}, \\
\Phi_{w}=\Phi_{w m} \frac{K C}{1+K C} .
\end{gathered}
$$

When $\gamma=1$, which corresponds to axial expansion, $\Phi_{w}$ is the adsorption capacity of water molecules by the film and $\Phi_{w m}$ is the maximum adsorption capacity of water molecules. $K$ is the equilibrium constant of water molecule adsorption and $C$ is the concentration of water molecules per unit volume.

When calculating the water concentration under different $\mathrm{RH}$ values, the $\mathrm{RH}$ of air is the actual water vapor density $\left(\rho_{1}\right)$ as a percentage of the saturated water vapor density $\left(\rho_{2}\right)$ :

$$
R H(\%)=\frac{\rho_{1}}{\rho_{2}} \times 100 \% .
$$

Since the relationship between the gas concentration and wavelength shift can be expressed as $\Delta \lambda \propto \Delta n \propto \Delta c$, ${ }^{(21)}$ the refractive index of the PVA gel is proportional to the amount of water absorption. From Eqs. (1) and (3)-(5), the change in the optical path difference can be obtained as

$$
\frac{\Delta L}{L}=\frac{\Delta n_{e}}{n_{e}}+\frac{\Delta d}{d}=\alpha \rho_{2} R H(\%)+\frac{k \Phi_{W m}}{\frac{1}{\rho_{2} R H(\%)}+k-k \Phi_{W m}} .
$$

From Eq. (6), we can see that the change in the optical path difference is directly related to $\mathrm{RH}$. Therefore, we can detect RH from the change in the interference spectrum.

\section{Experimental Results and Discussion}

\subsection{Humidity response experiment}

In this experiment, many standard saturated salt solution humidity bottles were used to provide environments with different humidity levels from 22 to $98 \%$ RH. As shown in Fig. 2, 


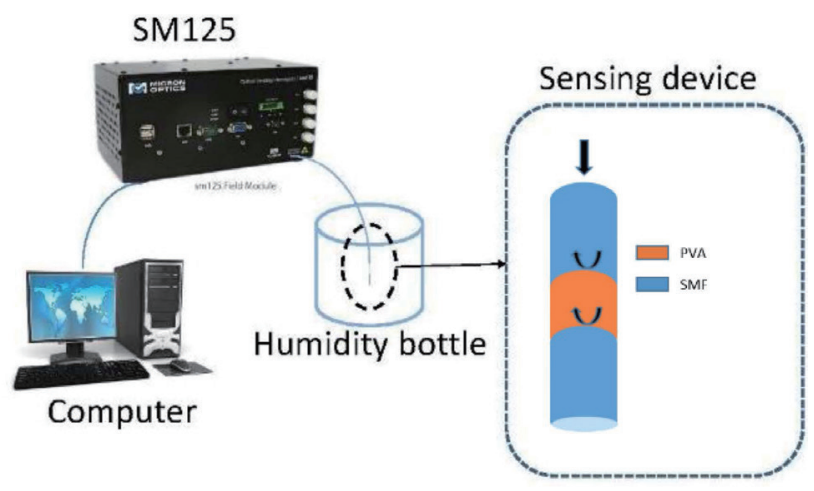

Fig. 2. (Color online) Experimental system for RH measurement.

the experimental system included the sensor, a humidity bottle, a Micron Optics SM125 optical fiber sensor analyzer, and a computer data acquisition and demodulation module. The output optical power of the SM125 analyzer was $18 \mathrm{~mW}$, the wavelength range was $1510-1590 \mathrm{~nm}$, the scanning frequency was $2 \mathrm{~Hz}$, the wavelength accuracy and stability were up to $1 \mathrm{pm}$, and the dynamic measurement range was $50 \mathrm{~dB}$. The analyzer was used both as a light source and for spectrum measurement. In the system, the light emitted from the analyzer entered the optical fiber F-P sensor and was reflected from the two reflective end faces of the F-P cavity. When the environmental humidity changed, the spectrum shifted. The relationship between the spectral data and the humidity could thus be measured.

The humidity response experiments were carried out in the humidity range of 22-98\% RH. We inserted the sensor into the humidity bottle and recorded the spectrum data. We repeated the same humidity measurement several times and changed the humidity bottle to change RH.

As RH increased, the peak wavelength shifted to the right, as shown in Fig. 3. This is mainly due to the interaction of the PVA material in the F-P cavity with water vapor, which changes the refractive index and cavity length. Thus, the peak wavelength shifted in accordance with Eq. (1) because of the change in the optical path difference between the two interference beams in the F-P cavity. This demonstrated that the sensor has useful humidity response characteristics.

In the experiment, the wavelength drift of each interference peak was collected. To reduce the error, the average value of the measured wavelength drift of each interference peak was used in the data processing under the same RH. Using these spectral data, the relationship between RH and peak wavelength shift was obtained. To verify the repeatability of the optical fiber humidity sensor, a cyclic measurement with rising and falling $\mathrm{RH}$ was also performed, the results of which are shown in Fig. 4.

In the experiment, the PVA concentration was $70 \mathrm{mg} / \mathrm{ml}$ and the cavity length was $137 \mu \mathrm{m}$. The initial humidity was $25 \% \mathrm{RH}$ and the temperature was $27.4{ }^{\circ} \mathrm{C}$. As shown in Fig. 4 , the humidity response has good linearity over a wide RH range with the rise or fall of RH. The sensitivity was $36.71 \mathrm{pm} / \%$ RH with 0.99773 linearity under rising humidity and $37.63 \mathrm{pm} / \%$ RH with 0.99846 linearity under falling humidity. The experimental results showed that the humidity sensor has good repeatability and consistency in both processes. The slight deviation 


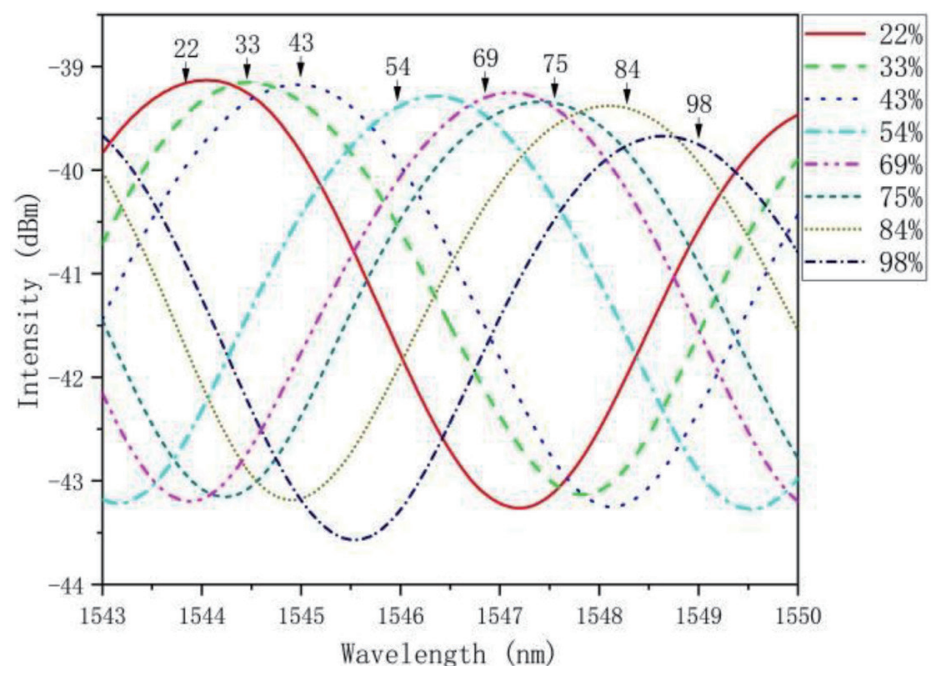

Fig. 3. (Color online) Response spectrum for different $\mathrm{RH}$ values.

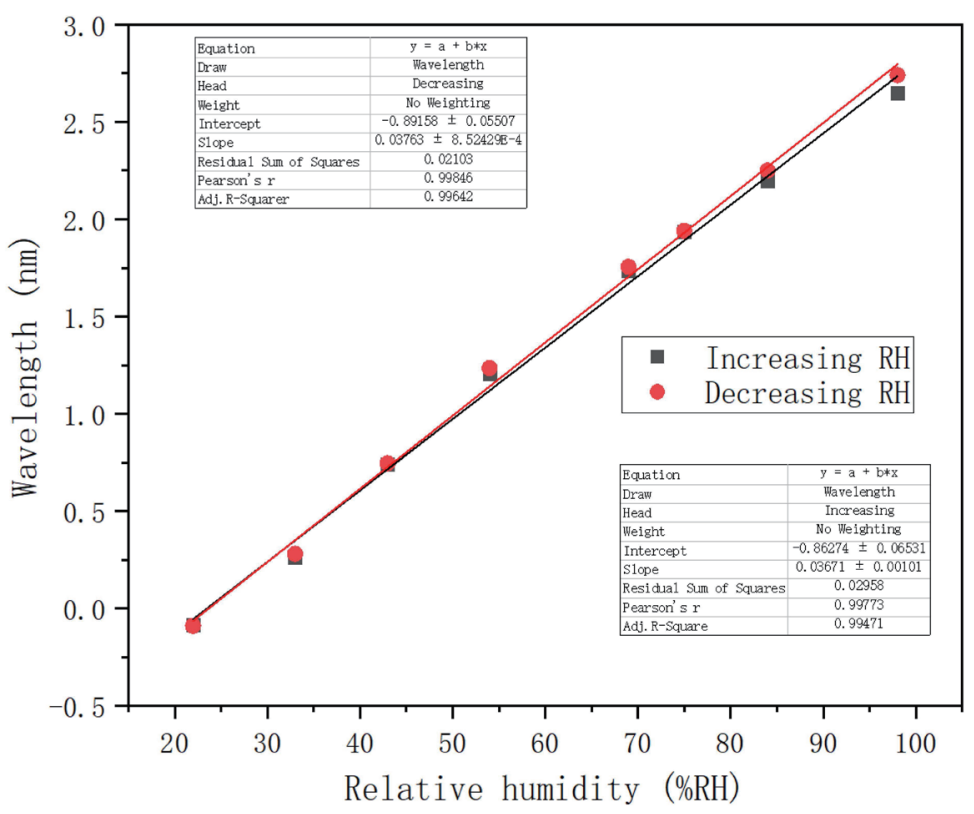

Fig. 4. (Color online) Peak wavelength shift as a function of RH.

between the rising and falling response curves at high $\mathrm{RH}$ in Fig. 4 is mainly due to the humidity error of the high-humidity saturated salt solution. To verify the stability of the sensor, the interference spectrum was continuously monitored under a specific RH for $30 \mathrm{~min}$, and the peak wavelength was found to be stable within $\pm 0.04 \mathrm{~nm}$. To consider the temperature response of the F-P cavity, the temperature was controlled by an incubator and monitored during the experiment, as shown in Fig. 5. Throughout the measurements, the maximum fluctuation of 


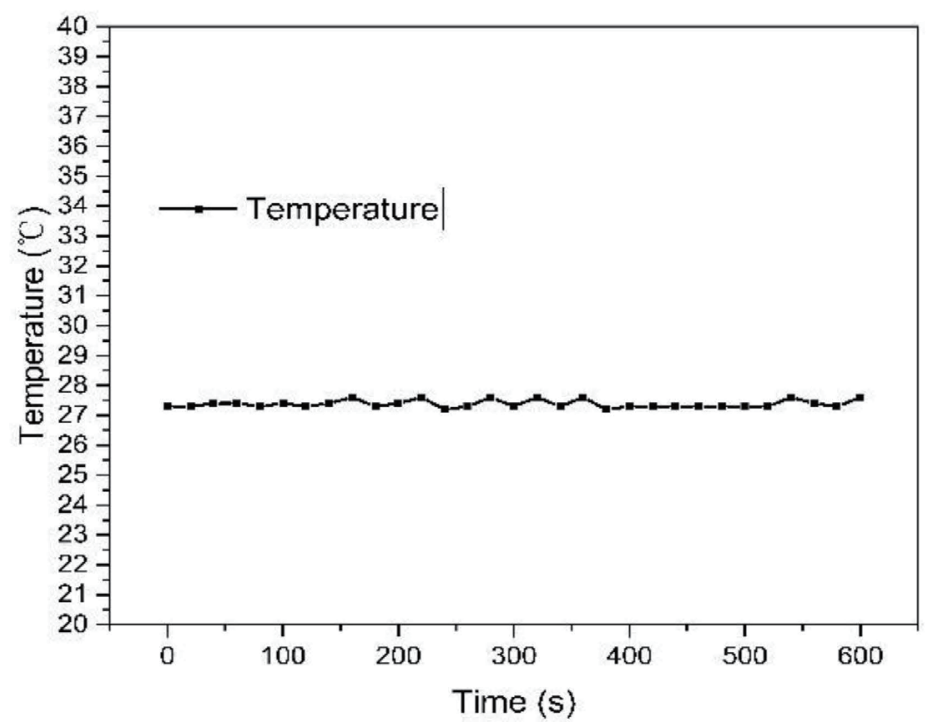

Fig. 5. Temperature monitoring data during experiment.

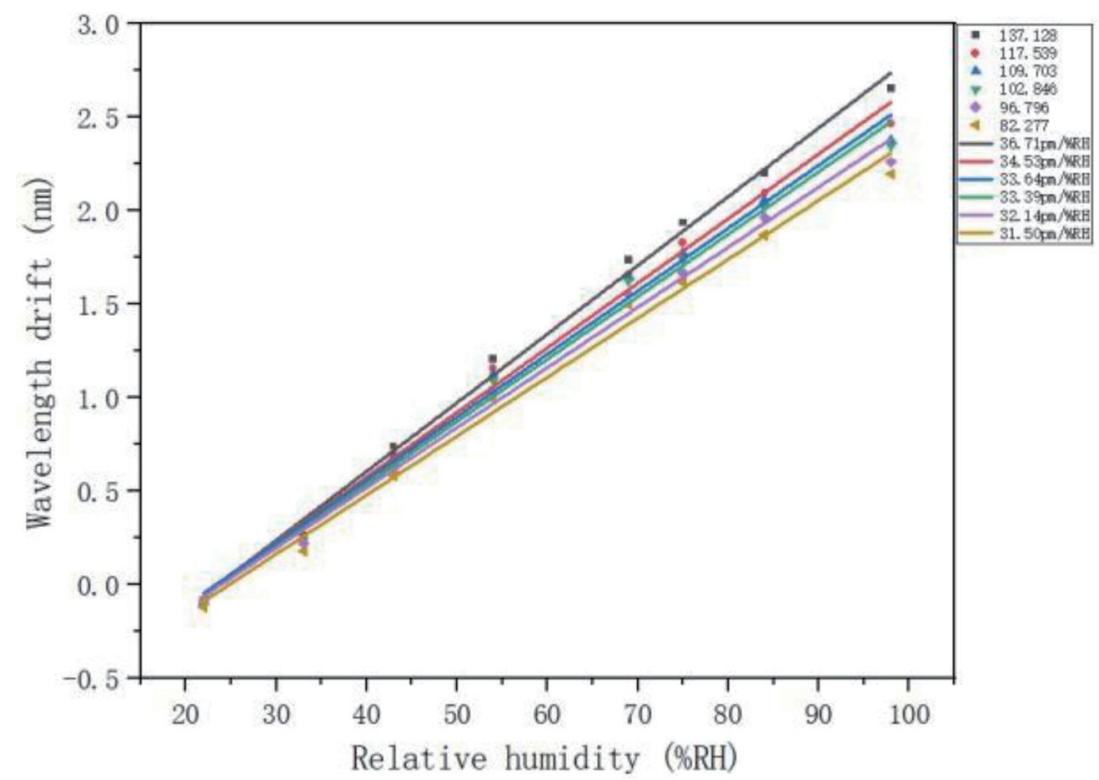

Fig. 6. (Color online) Response to humidity of sensors with different cavity lengths.

the environmental temperature was $0.3{ }^{\circ} \mathrm{C}$, which has no significant effect on the drift of the static humidity response spectrum. The good linear response in Fig. 4 demonstrated that the experimental error caused by the temperature fluctuation is very small.

To further investigate the humidity response characteristic for different F-P cavity lengths, six sensors with cavity lengths of $82,95,103,110,118$, and $137 \mu \mathrm{m}$ were separately tested in the humidity range of $22-98 \%$ RH, the results of which are shown in Fig. 6. 
All six sensors showed a good linear response over a wide range of $\mathrm{RH}$. As the length of the F-P cavity increased, the wavelength drift of the sensor and the slope of the fitted curve both increased, and thus the sensitivity increased. Therefore, a longer F-P cavity should be selected when obtaining the static or dynamic response of the sensor to ensure the efficiency of the experiment.

Furthermore, to explore the humidity response characteristic of sensors with different PVA concentrations, five sensors with PVA concentrations of 50,60, 70, 80, and $90 \mathrm{mg} / \mathrm{ml}$ were fabricated and their responses were measured at $22-98 \% \mathrm{RH}$. The experimental results are shown in Fig. 7.

All sensors showed a good linear response regardless of the PVA concentration. As the concentration of PVA increased, the wavelength drift and response sensitivity of the sensor also increased, which may be due to the change in the refractive index of the cavity. The sensitivity of the sensor can thus be improved by increasing the PVA concentration.

\subsection{Dynamic response experiment}

In our dynamic response measurements, the Micron Optics SM125 optical fiber sensor analyzer was set to automatic acquisition mode and the acquisition frequency was $2 \mathrm{~Hz}$. The computer could quickly obtain spectral changes. After ensuring the stability of the spectrum, the sensor was quickly placed in a saturated salt solution humidity bottle to observe the changes in the spectral waveform. Measurements were continued until the spectral waveform became stable, then the sensor was quickly removed from the humidity bottle. The sensor was inserted into the bottle and removed multiple times for repeated measurements. The spectrum data were continuously monitored throughout the measurements. Then we replaced the saturated

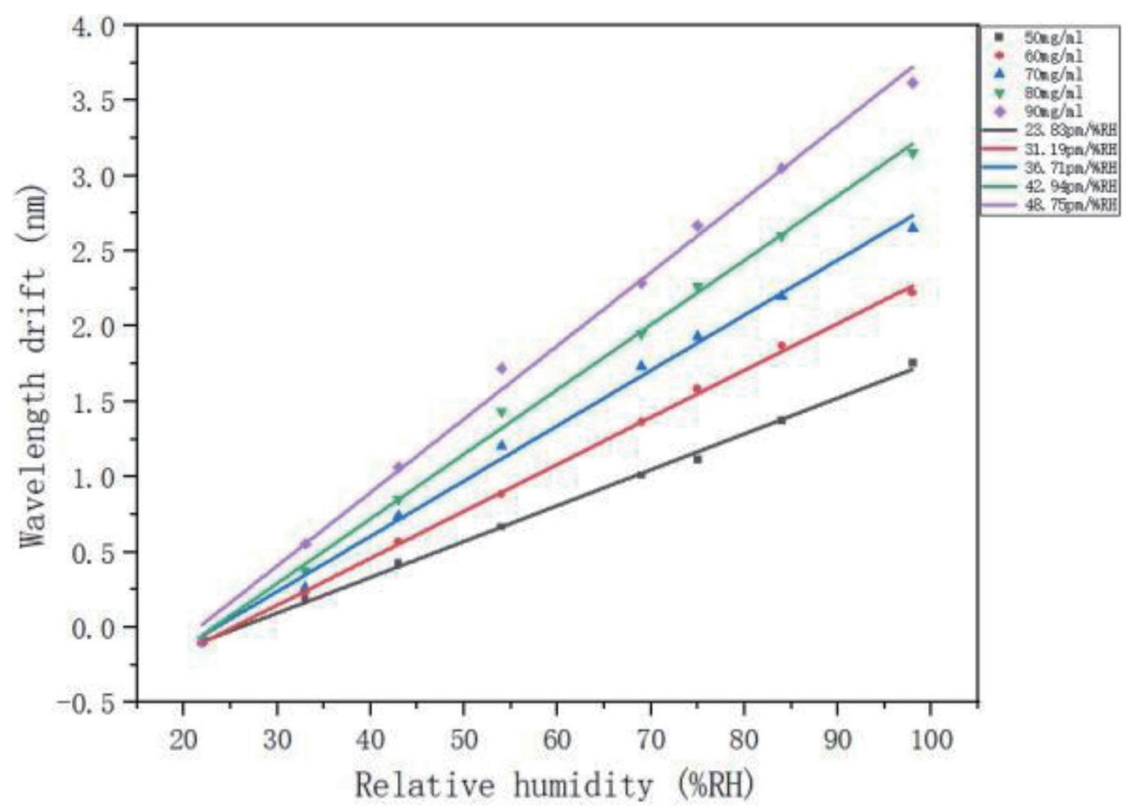

Fig. 7. (Color online) Fitted responses of sensors with different PVA concentrations. 
salt solution with one having a different humidity and repeated the above operation to obtain the next dynamic response to humidity, and the response to RH in the range of $22-98 \%$ was examined. The dynamic spectrum response data indicated the relationship between the drift of the interference peak wavelength and the monitoring time. Figure 8 shows the results of the dynamic response experiment for the sensor at $75 \% \mathrm{RH}$.

As shown in Fig. 8, the sensor exhibited clear changes in its dynamic response when it was inserted into and removed from the humidity bottle. Its peak wavelength drift and recovery were stable and repeatable. To obtain more details of the dynamic response, we analyzed the enlargement of a typical dynamic response result in Fig. 8 as shown in Fig. 9. The response and recovery times of the sensor were measured from 10 to $90 \%$ of the range of the wavelength drift. The response time of the sensor in Fig. 9 was $1.5 \mathrm{~s}$ and the recovery time was $2.5 \mathrm{~s}$. For further investigation, we show the independent dynamic response and recovery times of the sensor in eight environments with different $\mathrm{RH}$ values in Table 1. The response time of the sensor is between 1 and $2.5 \mathrm{~s}$ and the recovery time is between 2.5 and $3.5 \mathrm{~s}$. It can be seen that the sensor has a good dynamic response capability.

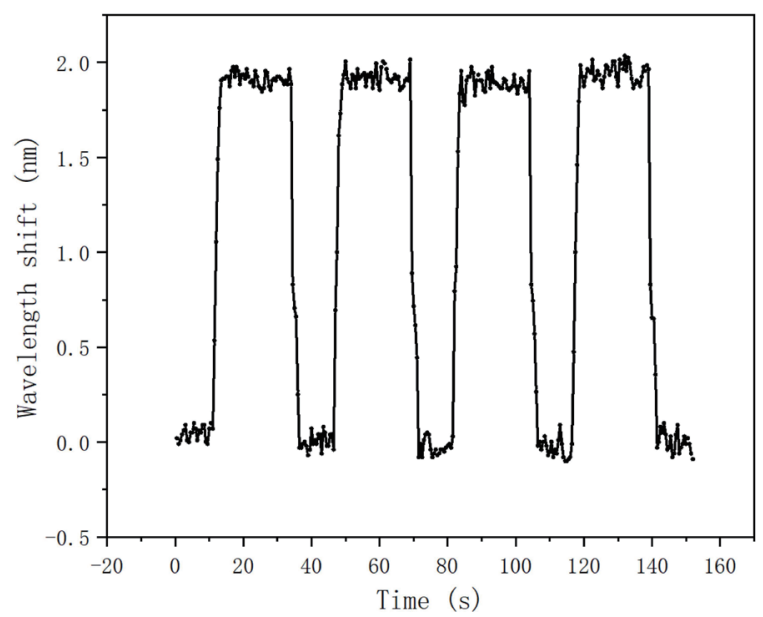

Fig. 8. Dynamic response spectrum at $75 \% \mathrm{RH}$.

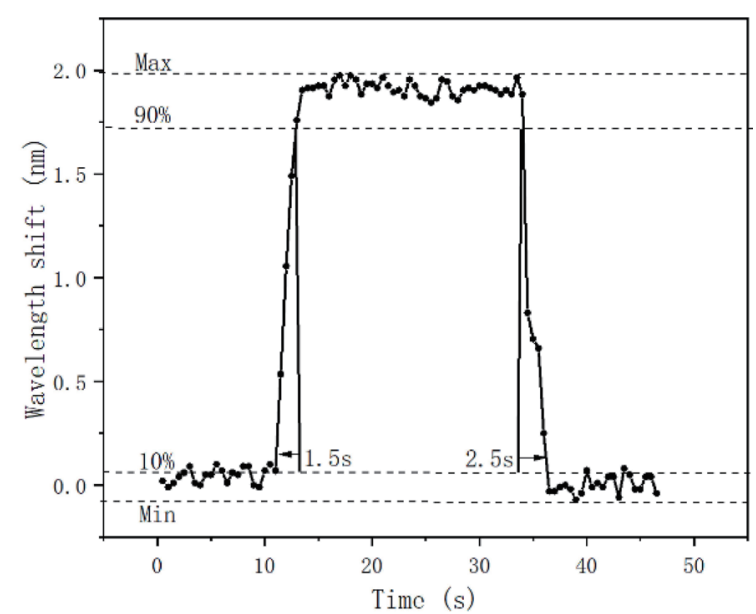

Fig. 9. Response time and recovery time at $75 \%$ RH.

Table 1

Response and recovery times for different $\mathrm{RH}$ values.

\begin{tabular}{lcc}
\hline RH (\%) & Response time (s) & Recovery time (s) \\
\hline 22 & 2.5 & 3 \\
33 & 2.5 & 3.5 \\
43 & 2 & 3.5 \\
54 & 2 & 3.5 \\
69 & 1 & 3.5 \\
75 & 1.5 & 2.5 \\
84 & 1.5 & 3 \\
98 & 1.5 & 3.5 \\
\hline
\end{tabular}


Table 2

Comparison with other optical fiber humidity sensors.

\begin{tabular}{lccccc}
\hline Reference & Type & $\begin{array}{c}\text { Humidity-sensitive } \\
\text { material }\end{array}$ & RH (\%) & Sensitivity & $\begin{array}{c}\text { Response \& } \\
\text { recovery times (s) }\end{array}$ \\
\hline$(22)$ & F-P interferometer & PVA-GQDs & $11.3-83.4$ & $0.11725 \mathrm{~nm} / \% \mathrm{RH}$ & - \\
\hline$(23)$ & $\begin{array}{c}\text { Etched side-hole fiber } \\
\text { sandwiched with coating }\end{array}$ & PVA & $30-90$ & $-23.1 \mathrm{pm} / \% \mathrm{RH}$ & $0.66,0.96$ \\
\hline$(24)$ & TCF & CNT/PVA & $\begin{array}{c}25.7-67.7 \\
67.7-89\end{array}$ & $\begin{array}{c}-0.0235 \mathrm{~nm} / \% \mathrm{RH} \\
-0.271 \mathrm{~nm} / \% \mathrm{RH}\end{array}$ & 1,2 \\
\hline$(25)$ & $\begin{array}{c}\text { Side-polished twin-core } \\
\text { fiber }\end{array}$ & Graphene oxide & $\begin{array}{c}40-75 \\
60-62.1\end{array}$ & $\begin{array}{c}2.72 \mathrm{~nm} / \% \mathrm{RH} \\
3.76 \mathrm{~dB} / \% \mathrm{RH}\end{array}$ & $3.6,6.4$ \\
\hline$(26)$ & $\begin{array}{c}\text { Microstructured fiber } \\
\text { Bragg grating }\end{array}$ & Polycarbonate & $20-90$ & $0.00731 \mathrm{~nm} / \% \mathrm{RH}$ & $10.5,25$ \\
\hline (27) & U-shaped microfiber & PVA & $30-95$ & $\begin{array}{c}186.5 \mathrm{pm} / \% \mathrm{RH} \\
\text { (nonlinear) }\end{array}$ & - \\
\hline Our work & F-P interferometer & PVA & $22-98$ & $37.16 \mathrm{pm} / \% \mathrm{RH}$ & $1.5,2.5$ \\
\hline
\end{tabular}

Note that the response time of the sensor is shorter than the recovery time. The main reason for this is related to the PVA material filled in the F-P cavity, which takes different amounts of time to absorb and release water because of its humidity-sensitive character. Simultaneously, the dynamic response speed is very stable at different $\mathrm{RH}$ values according to Table 1 . The dynamic response capability can thus be maintained over a wide range of RH.

Table 2 shows a comparison between the proposed sensor and some other optical fiber humidity sensors that have been reported. Compared with the other humidity sensors, our sensor has better response linearity with a wider linear response range or a higher response speed. Although the sensors in Refs. 22 and 27 had high sensitivity, their response speed was not investigated, and costly materials such as U-shaped microfibers were required. The sensor in Ref. 23 had a faster response but a slightly lower sensitivity; this sensor was fabricated using etched side-hole fibers sandwiched with a coating, which involved a complex process and the use of high-cost special fibers. The sensitivity of our sensor is higher than that of the sensors in Refs. 24 and 26. In addition, the sensor in Ref. 25 had a large sensitivity gap in different humidity ranges and the measurement range was limited. The repeatability and linearity of the response of our sensor were reasonably good throughout the entire humidity cycle test.

\section{Conclusions}

In this study, an optical fiber F-P humidity sensor was fabricated using PVA as a humiditysensitive material and normal single-mode optical fibers. In the range of $22-98 \% \mathrm{RH}$, a significant response to the RH of the environment was verified. The sensitivity was $36.71 \mathrm{pm} / \%$ RH under rising humidity and $37.63 \mathrm{pm} / \%$ RH under falling humidity. The humidity sensor had good stability and repeatability in both cases, with a linear response over a wide range. Many repeated experiments with different PVA concentrations and cavity lengths also verified that the sensor not only has good linear response characteristics but also has high repeatability. Typical tests were carried out to investigate the dynamic response of the sensor, which showed that the 
sensor has a short response time to humidity changes. However, owing to the difference in the rates of the absorption and removal of moisture by PVA, the sensor response and recovery times are different. This sensor has a good humidity response performance with a simple and low-cost fabrication process, demonstrating the possibility of easily fabricating low-cost optical fiber humidity sensors with good performance.

\section{Acknowledgments}

This research was supported by the National Natural Science Foundation of China (No. 61805285), the Graduate Innovation Engineering Project (YCX2020118), and the National Training Program of Innovation and Entrepreneurship for Undergraduates (Nos. 202012047 and 20190496).

\section{References}

1 Ravikant, S. Singh, G. Gupta, S. Yadav, P. K. Dubey, V. N. Ojha, and A. Kumar: Sens. Actuators, A 295 (2019) 133. https://doi.org/10.1016/j.sna.2019.05.023

2 Y.-H.Wang, R. W. Beasant, C. J. Simonson, and S. Wei: Sens. Actuators, B 115 (2005) 93. https://doi. org/10.1016/j.snb.2005.08.038

3 P. J. Thomas and J. O. Hellevang: Sens. Actuators, B. 270 (2018) 417. https://doi.org/10.1016/j.snb.2018.05.011

4 V. Bhatia, K. A. Murphy, R. O. Claus, T. A. Tran, and J. A. Greene: Smart Mater. Struct. 4 (1995) 246. https:// doi.org/10.1088/0964-1726/4/4/004

5 Z. Ran, Y. Rao, Z. Jian, Z. Liu, and X. Bing: J. Lightwave Technol. 27 (2009) 5426. https://doi.org/10.1109/ JLT.2009.2031656

6 D. L. Franzen and E. M. Kim: Appl. Opt. 20 (1981) 3991. https://doi.org/10.1364/AO.20.003991

7 A. D. Kersey, D. A. Jackson, and M. Corke: Opt. Commun. 45 (1983) 71. https://doi.org/10.1016/00304018(83)90047-0

8 F. Mitschke: Opt. Lett. 17 (1989) 967. https://doi.org/10.1364/OL.14.000967

9 N. Wang, W.-H. Tian, and H.-S. Zhang: Acta Photonica Sinica. 49 (2020) 107. https://doi.org/10.3788/ gzxb20204909.0906003

10 L. H. Chen, T. Li, C. C. Chan, R.Menon, P. Zu, M. Shaillender, B. Neu, X. M. Ang, W. C. Wong, and K. C. Leong: Sens. Actuators, B 169 (2012) 167. https://doi.org/10.1016/j.snb.2012.04.052

11 X. Wei, W.-B. Huang, X.-G. Huang, and C.-Y. Yu: Opt. Fiber Technol. 19 (2013) 583. https://doi.org/10.1016/ j.Yofte2013.09.005

12 D. Ailincai, G. Gavril, and L. Marin: Mater. Sci. Eng. C 107 (2020) 110316-1.https://doi.org/10.1016/ j.msec.2019.110316

13 J. A. da Cruz, A. B. da Silva, B. B. S. Ramin, P. R. Souza, K. C. Popat, R. S. Zola, M. J. Kipper, and A. F. Martins: Mater. Sci. Eng. C 107 (2020) 110357-1. https://doi.org/10.1016/j.msec.2019.110357

14 S. Alipoori, M. M. Torkzadeh, M. H. M. Moghadam, S. Mazinani, S. H. Aboutalebi, and F. Sharif: Polymer 184 (2019) 121908-1. https://doi.org/10.1016/j.polymer.2019.121908

15 H.-B. Huang and H.-Y. Huang: Sens. Techol. 6 (1988) 48. https://doi.org/10.13873/j.1000-97871988.04.014

16 Y.-P. Miao, B. Liu, J. Liu, H. Sun, and Q.-D. Zhao: Optoelectron.'Laser 21 (2010) 978. https://doi.org/10.16136/ j.joel.2010.07.032

17 C.-Q. Zhu: Tapered Optical Fiber Humidity Sensor Research Based on Humidity Sensitive Film, Master's thesis, Yanshan University (2014). https://cdmd.cnki.com.cn/Article/CDMD-10216-1014041425.htm

18 X.-M. Tang, J.-L. An, and Y.-X. Jin: Laser Optoelectron. Progress. 51 (2014) 42. https://doi.org/10.3788/ LOP51.060603

19 W.-H. Bi, C.-Q.Zhu, X.-H. Fu, G.-W. Fu, and B.-J.Zhang: Optoelectron. Laser 25 (2014) 1443. https://www. cnki.com.cn/Article/CJFDTOTAL-GDZJ201408001.htm

20 C. Y. Lee and M. S. Strano: Langmuir 21 (2005) 5192. https://doi.org/10.1021/la046867i

21 X.-L. Liu: Research on Fiber Gas Sensors Based on Graphene Oxide, Master's thesis, University of Electronic Science and Technology of China (2017). https://cdmd.cnki.com.cn/Article/CDMD-10614-1017077829.htm

22 Y. Zhao, R. J. Tong, M. Q. Chen, and F. Xia: Sens. Actuators, B 284 (2019) 96. https://doi.org/10.1016/ j.snb.2018.12.130 
23 S.-N. Wu, G.-F. Yan, Z.-G. Lian, X. Cheng, B. Zhou, and S.-L. He: Sens. Actuators, B 225 (2016) 50. https:// doi.org/10.1016/j.snb.2015.11.015

24 Q.-F. Ma, Z.-Q. Tou, K. Ni, Y.-Y. Lim, Y.-F. Lin, Y.-R. Wang, M.-H. Zhou, F.-F. Shi, L. Niu, X.-Y. Dong, and C.-C. Chan: Sens. Actuators, B 257 (2018) 800. https://doi.org/10.1016/j.snb.2017.10.121

25 R. Chu, C. Guan, Y. Bo, J. Shi, Z. Zhu, P. Li, J. Yang, L. Yuan: Sens. Actuators, B 284 (2019) 623. https://doi. org/10.1016/j.snb.2019.01.011.

26 R. J. Tong, Y. Zhao, M. Q. Chen, and Y. Peng: Sens. Actuators, A 280 (2018) 24. https://doi.org/10.1016/ j.sna.2018.07.024

27 Y. Zhao, Y. Peng, M.-Q. Chen, and R.-J. Tong: Sens. Actuators, B 263 (2018) 312. https://doi.org/10.1016/ j.snb.2018.02.123 